\title{
Revitalisasai dan Pola Penataan Masa Bangunan pada SMP Negeri 3 Batu Provinsi Jawa Timur
}

\author{
Enggal Chairyadi Mulyono \\ Universitas Nahdlatul Ulama Blitar, Indonesia \\ Email: enggal.chairyadi@gmail.com
}

\begin{tabular}{l}
\hline Tersedia Online di \\
\hline http://www.jurnal.unublitar.ac.id/in \\
dex.php/briliant \\
\hline \\
\hline Sejarah Artikel \\
Diterima pada 30 Oktober 2019 \\
Disetujui pada 29 November 2019 \\
Dipublikasikan pada 30 November \\
2019 Hal. 594- \\
\hline
\end{tabular}

Kata Kunci:

Revitalisasi, Penataan-Massa, Lingkungan

DOI:

http://dx.doi.org/10.28926/briliant.v $4 \mathrm{i} 4.378$

\begin{abstract}
Abstrak: Pengembangan Sarana prasarana dalam dunia pendidikan merupakan salah satu upaya yang penting untuk diperhatikan dalam menunjang dan meningkatkan proses pembelajaran di sekolah. Melihat kondisi tersebut, dipandang perlu dan segera untuk memenuhi kebutuhan sarana pendidikan berwawasan lingkungan baik ditingkat regional, nasional maupun internasional. Maksud dan tujuan dari kegiatan Perencanaan Revitalisasi Kawasan Lingkungan Pendidikan SMPN 03 Berwawasan Lingkungan, meningkatkan mutu kinerja sekolah, Mendukung terciptanya Kota Batu sebagai kota pendidikan, memberikan tempat belajar, menyediakan, melengkapi dan memperbarui fasilitas dan bangunan pendidikan. Hasil perencanaan yang telah dikaji ini akan menjadi konsep yang sesuai.
\end{abstract}

\section{PENDAHULUAN}

Pengembangan Sarana prasarana dalam dunia pendidikan merupakan salah satu upaya yang penting untuk diperhatikan dalam menunjang dan meningkatkan proses pembelajaran di sekolah. Peningkatan dalam pendayagunaan dan pengelolaannya menjadi acuan penting untuk tercapainya tujuan. Pengelolaan sarana prasarana, lingkungan, fasilitas sekolah dapat menjadi motivasi untuk meningkatkan kualitas pendidikan. Manajemen sarana prasarana pendidikan tidak lepas dari sebuah perencanaan dan pengembangan. Seiring dengan berjalannya waktu dan adanya otonomi daerah, sekolah dituntut mandiri dalam mengatur kebutuhan sekolah dengan tetap mengacu pada peraturan dan undang undang pendidikan nasional (Darmawan, 2014)

Dengan berkembang pesatnya ilmu pengetahuan dan teknologi di era globalisasi dunia ini membawa pengaruh terhadap dunia pendidikan. Pemerintah memiliki peran penting dalam peningkatan mutu pendidikan untuk menciptakan sekolah yang sehat dan asri guna meningkatkan kualiatas SDM didalamnya. Salah satu upaya yang perlu diperhatikan adalah pembangunan sarana prasarana dan fasilitas sekolah dapat mendukung program pendidikan dalam proses belajar mengajar. Sarana dan Prasarana pendidikan menjadi tolak ukur mutu dalam meningkatkan kualitas sekolah dan perlu secara terus menerus melakukan peningkatan dan perkembangan ilmu pengetahuan dan teknologi (Sinta, 2019). 
Dalam melakukan pengembangan sekolah salah satu aspek penting yang perlu dilakukan adalah sebuah perencanaan yang matang. Perencanaan inilah yang nantinya akan menjadi acuan pelaksanaan pengembangan sekolah dapat dilakukan. Sebuah perencanaan atau pembangunan tidak akan lepas dari ide konsep dan desain arsitektur dengan memperhatikan lingkungan asli dan sekitarnya (Sugiyarto, 2017). Salah satu aspek yang kurangnya diperhatikan dalam dunia pembangunan adalah penataan energi. Kurangnya perhatian dalam pengelolaan sumber energi tak terbaharui mendorong arsitek untuk peduli dalam pemanfaatannya sehingga sumber tersebut beralih ke sumber energi yang terbaharui dalam mengembangkan bangunan yang hemat energi (Simbolon, 2017). Pendekatan konsep desain berwawasan lingkungan sangat perlu dilakukan untuk menghadapi global warming. Diharapkan dengan adanya pendekatan ini dapat menyeimbangkan alam guna menjaga dan mengurangi pemanasan secara global. Pembangunan berwawasan lingkungan adalah pembangunan yang dapat memilihara kelestarian lingkungan dengan meningkatkan sumber energi dan sumber alam yang hampir rusak (Ervianto, 2012)

Prasarana menjadi kebutuhan pokok yang perlu dipertimbangan dalam pengembangannya, dengan melakukan penataan ulang menjadi tahap perencanaan untuk mengembangan mutu di dunia pendidikan. Salah satu sekolah yang mendapat perhatian dalam pengembangan sarana dan prasarananya untuk segera dikaji adalah SMP Negeri 03 Batu, Jawa Timur "berwawasan lingkungan". Kebutuhan sarana dan prasarana serta fasilitas pendukung yang memadai dikawasan ini terus meningkat seiring dengan laju perkembangan daerah sekitar guna tercapai kenyamanan dalam kegiatan belajar mengajar. Perencanaan pembangunan harus dibangun secara jelas atau memiliki fungsi, dimana dapat menampung segala aktivitas dan kebutuhan yang ada. Untuk memenuhi kebutuhan sarana pendidikan yang lebih baik yaitu sehat dan arsi perlu dilakukannya pendekatan pembangunan dan revitalisasi yang berwawasan lingkungan. Sehingga menjadi motivasi bagi siswa dalam menimba ilmu dan skill/keahlian untuk mencetak generasi yang bisa bersaing baik ditingkat regional, nasional maupun internasional.

Dari pembahasan diatas maka perlu dilakukannya kegiatan Perencanaan Revitalisasi Kawasan Lingkungan Pendidikan SMP Negeri 03 Batu, Jawa Timur "Berwawasan Lingkungan" dengan melakukan pendekatan konsep perencanaan yang ramah lingkungan dan hemat energi : Merencanakan Sarana Prasarana yang lebih asri guna meningkatkan mutu sekolah untuk mempersiapkan lulusan yang berkualitas dan mendukung terciptanya Kota Batu sebagai kota pendidikan dan kota pariwisata yang mencerminkan profil ekonomi Kota Batu. merencanakan tempat belajar yang lebih nyaman dan sehat bagi mendukung aktifitas belajar. Merencanakan fasilitas dan bangunan pendidikan yang ada di SMP Negeri 03 Batu untuk menciptakan sekolah atau lembaga pendidikan yang memenuhi kebutuhan beraktifitas dan dapat tetap menjaga keseimbangan lingkungan sekitar dan kelestarian alam sekitar. Perencanaan Revitalisasi Kawasan Lingkungan Pendidikan SMP Negeri 3 Batu, Jawa Timur "Berwawasan Lingkungan" diharapkan menjadi acuan sekolah lainnya sebagai cerminan fisik yaitu perwujudan visualisasi perencanaan. Menjadikan sarana dan prasarana SMP Negeri 03 Batu, Jawa Timur yang berwawasan lingkungan tersebut dapat mendukung dan meningkatkan aktifitas belajar siswa. Dan proses akhir dari 
pelaksanaan Perencanaan Revitalisasi Kawasan Lingkungan Pendidikan SMP Negeri 03 Batu, Jawa Timur ini dapat Melestarikan lingkungan sekitar.

\section{METODE}

Penelitian ini menggunakan metode survei, studi obyek/lapangan dan studi literatur. Dalam penelitian ini penulis mengambil obyek kajian pada SMP Negeri 03 Batu, Jawa Timur dengan batasan obyek yang dikaji adalah perencanaan pagar, landscape dan ruang belajar. Instrument penelitian meliputi: survei dan pengukuran, penentuan tata letak, analisa tapak, desain arsitek, penentuan tahap pelaksanaan pembangunan dengan skala prioritas.

Tahap pengumpulan data: pada tahap ini perencana melakukan pengumpulan data dengan dua cara yaitu denga melakukan observasi dan pengumpulan data tertulis.

○ Observasi

Pada metode ini perencana mengumpulkan data awal dengan melakukan eset (survei awal) yaitu memantau kondisi lapangan existing dengan menampung informasi yang ada dilapangan, melakukan evaluasi kondisi lahan, misalnya kondisi ruang, daya tampung ruang, pola-pola aktivitas dalam ruangan maupun antar ruangan, pola-pola sirkulasi sesuai pola-pola pergerakan atau aktivitas dan sebagainya.

- Pengumpulan Data Tertulis

Pada metode ini perencana mengumpulkan data-data yang berkaitan dengan statistik atau angka-angka, standar-standar khusus bagi perkantoran, standarstandar sesuai ketentuan atau peraturan yang berlaku, termasuk data mengenai peralatan yang dibutuhkan dan kemungkinan penambahan peralatan.

Tahap analisa: pada tahap ini perencana melakukan analisa dalam menyusun konsep dengan penerapan arsitektur berwawasan lingkungan dengan tahapan sebagai berikut: analisa tapak, analisa kebutuhan ruang, analisa bentuk, analisa sistem struktur bangunan, analisa sistem utilitas bangunan.

Tahap Konsep: pada tahap ini merupakan tahap perencanaan konsep menerjemahkan informasi, analisa dan keinginan pengguna dan permasalahan yang adala dilokasi existing.

Tahap Desain: pada tahap ini merupakan tahap lanjutan dari ide konsep atau pra desain menjadi desain gambar proporsional denga melakukan pengembangan pada gambar-gambar kerja sebelumnya.

Tahap Gambar Rancangan/dokumen perencanaan: pada tahap ini merupakan tahap akhir berupa gambar kerja terskala setelah melewati tahap pengujian sehingga ide konsep dan sketsa desain tersebut menjadi tolak ukur dan patokan untuk gambar detail perencanaan. Gambar Perencanaan terskala meliputi, Rencana induk, rencana tapak, denah, tampak, potongan, detail struktur dan elektrikal mekanikal.

\section{HASIL}

Hasil revitalisasi dan pola penataan massa banguna pada kawasan lingkungan pendidikan SMP Negeri 03 Batu, Jawa Timur ini adalah merencanakan kawasan yang berwawasan lingkungan dengan menggunakan bahan produksi dalam negeri untuk menjamin mutu dan standar yang dibutuhkan 
untuk klasifikasi bangunan gedung Negara. Perencanaan menggunakan kualitas bahan Standart Nasional Indonesia (SNI), Pola penataan disesuaikan dengan kondisi eksisting. Memperhatikan fungsi kegiatan dan kebutuhan ruang serta sinar matahari secara langsung. Strategi perencanaan/perancangan dilakukan melalui metode perancangan arsitektur (architectural programming - donna duerk) dan di simulasi dengan software ecotect. peran arsitektur berwawasan lingkungan yang hemat energy dapat terealisasi dengan baik, Penanaman vegetasi di area revitalisasi lingkungan pendidikan.
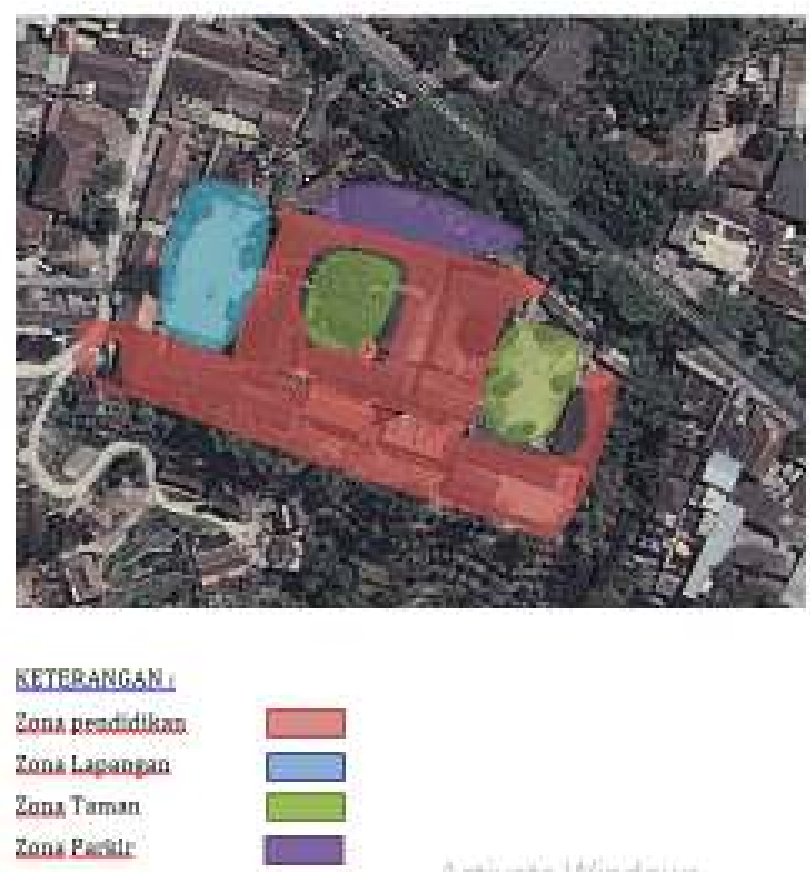

Gambar 1. Konsep Tata Massa Lingkungan SMP Negeri 03 Batu, Jawa Timur.

Gambar 1 merupakan konsep tata massa lingkungan SMP Negeri 03 Batu, Jawa Timur. Dimana kawasan tersebut merupakan zonasi existing kawasan lingkungan sekolah yang akan dikembangan. Dari analisa tapak kawasan ini perlu dilakukan revitalisasi untuk melestarikan kembali keasrian kawasan ini dengan memanfaatkan vegetasi dengan melakukan penghijauan pada spot yang sudah ditentukan Strategi perencanaan/perancangan dilakukan melalui metode perancangan arsitektur (architectural programming - donna duerk) dan di simulasi dengan software ecotect. Peran arsitektur berwawasan lingkungan yang hemat energi dapat terealisasi dengan baik, penanaman vegetasi di area revitalisasi lingkungan pendidikan, yang dapat dilihat dari hasil perencanaan pada Gambar 2 sebagai berikut : 


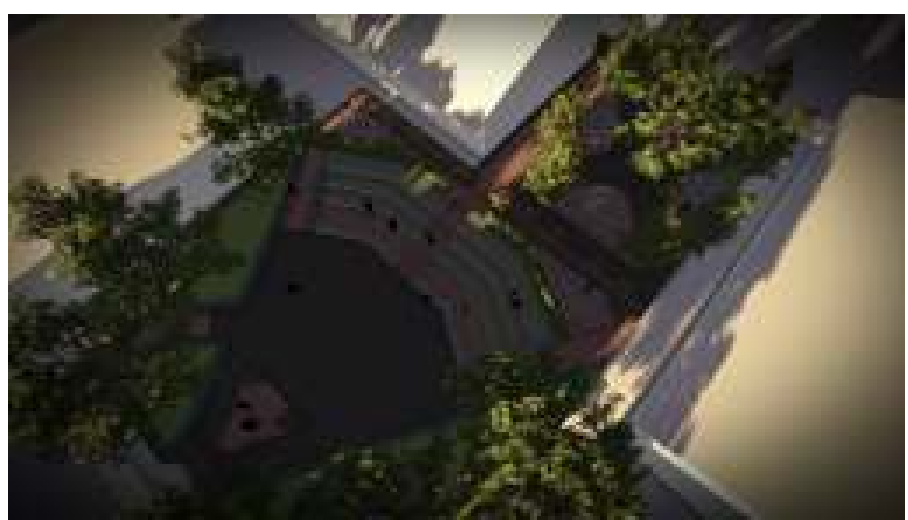

Gambar 2. Spot Terbuka Hijau atau taman terbuka

Pada Gambar 2 diatas terlihat zona tersebut merupakan zona area terbuka hijau yang difungsikan untuk berkumpulnya dan berinteraksi para siswa. Zona tersebut menjadi vocal point pada kawasan sekolah ini. Penerapan konsep ini bertujuan agar siswa dapat bersatu dengan alam dan termotivasi untuk melestarikan lingkungan sekolah. Konsep perencanaan, pada hakekatnya perencanaan suatu bangunan didasarkan atas prediksi perkembangan hingga kurun waktu tertentu, dalam hal ini perencanaan revitalisasi kawasan lingkungan pendidikan SMPN 3 Batu berwawasan lingkungan dibuat untuk perkembangan hingga sepuluh tahun yang akan datang. Penerapan dan pendekatan konsep desain berwawasan lingkungan ini direncakanan disetiap zona yang telah ditentukan untuk dilakukannya pengembangan. Hasil desain tersebut dapat dilihat pada Gambar 3 sebagai berikut:

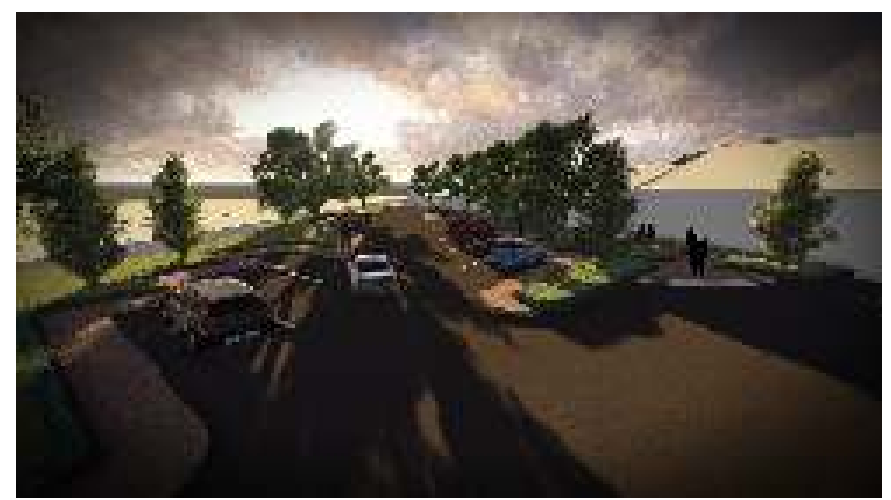

Gambar 3. Spot Parkir

\section{PEMBAHASAN}

Proses dan tahap perencanaan pada kawasan SMP Negeri 3 Batu, Jawa Timur "berwawasan lingkungan" ini dilakukan secara bertahap atau berkelanjutan. Tahapan-tahapan yang akan dilaksanakan dalam pengembangan sekolah ini adalah sebagai berikut :

1. Perencanaan Teknis

Pada tahap ini perencana membuat rencana tapak, pra rencana, dan gambar kerja.

2. Penyusunan Rencana / Rancangan Teknis Pelaksanaan

Pada tahap ini perencana membuat konsepsi perencanaan/perancangan teknis secara keseluruhan dengan meninjau dan melaraskan sistem didalamnya; 
menyiapkan sistem konstruksi dan struktural bangunan serta instalasi teknis; menjelaskan bahan bangunan yang akan digunakan.

3. Perencanaan Keputusan Desain

Pada tahap ini perencana dapat mengilustrasikan dan menrjemahkan hasil dari analisa desain dengan menyaring, melakukan tahap pengujian dan evaluasi desain. Melakukan review kembali, verifikasi dan membuat skala prioritas dan menyiapkan beberapa alternatif desain.

4. Dokumen Pelaksanaan

Pada tahap ini perencana membuat laporan akhir berupa dokumen pelaksanaan secara detail tentang rencana arsitektur dan struktur yang digunakan. Membuat dokumen administrasi dan persyaratan umum serta khusus. Dan terakhir melengkapi dan menyiapkan gambar kerja dan detail perencanaan.

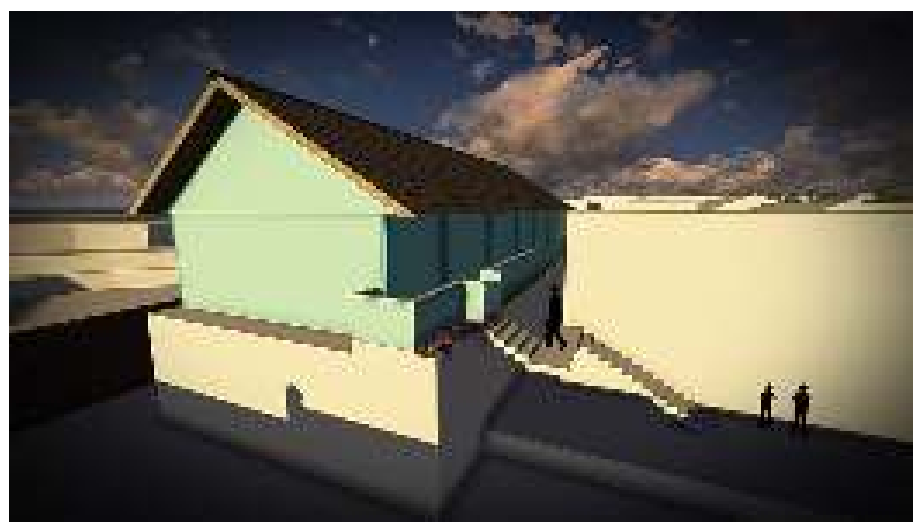

Gambar 4. Gedung Kelas 3d

Gambar 4 merupakan visualisasi gedung siswa dalam bentuk tiga dimensi atau perspektif mata burung. Terlihat pada perencanaan gedung ini menerapkan kearifan lokal yaitu menjaga konsep gedung dengan merencakan gedung yang tropis untuk bertahan dari iklim indonesia, keasrian dengan adanya bunga disekitar kelas dan pemagaran untuk memberikan area batas atau zona privasi sekolah dengan lingkungan luar.

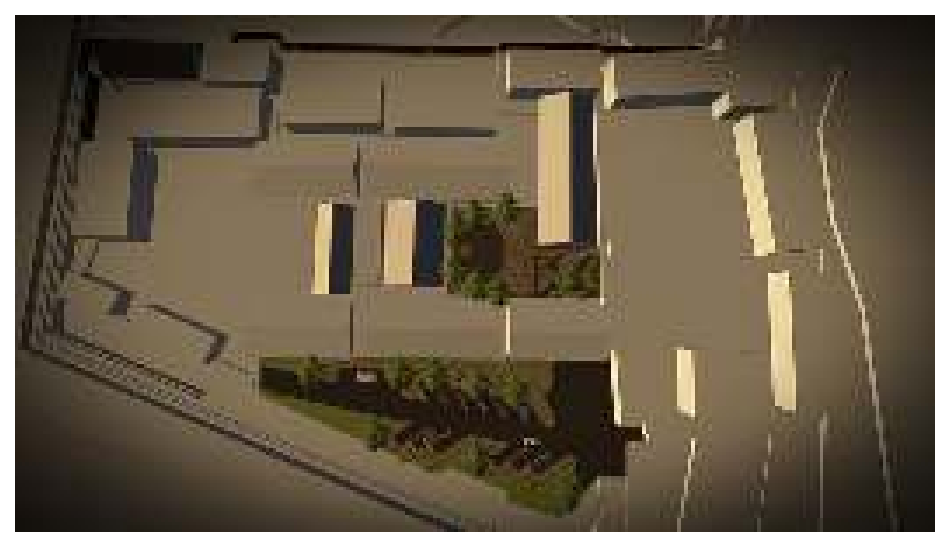

Gambar 5. Masterplan 3d

Pada Gambar 5 terlihat area putih merupakan kawasan zona gedung kelas dan pagar sedangkan area berwarna merupakan spot atau vocal point yang 
merupakan konsep penting dalam pengembangan kawasan SMP Negeri 3 Batu, Jawa Timur ini. Dengan adanya area parkir dan area terbuka hijau ini diharapkan dapat mengembalikan kelesatarian alam dilingkungan sekolah, menjadi contoh masyarakat sekitar dan siswa untuk lebih peduli dengan lingkungan, dan menjadi wadah untuk mahasiswa lebih mengenal alam dalam melakukan aktifitas mereka di dunia pendidikan guna meningkatkan mutu pendidikan dan kegiatan belajar mengajar.

\section{KESIMPULAN}

Berdasarkan dari hasil perencanaan yang telah dilakukakan yaitu Revitalisasi dan Pola Penataan Masa Bangunan pada SMP negeri 03 Batu, Jawa Timur dengan tahapan tahapan desain yang telah dilakukan maka dapat diambil kesimpulan antara lain: 1) Untuk mendapatkan perencanaan gedung "berwawasan lingkungan" perencanaan harus menerapkan dan melakukan pendekatan kawasan yang berkelanjutan dimana perlu dilakukakannya penyegaran atau pelestarian pada kawasan sekitar dengan memanfaatkan penanaman vegetasi kembali pada kawasan lingkungan sekolah. 2) Hasil perencanaan yang telah dihasilkan dari perencanaan ini menjadi penerapan konsep yang sesuai dengan penugasan yang diberikan oleh Pengguna Anggaran dengan merealisasikan cita-cita pengguna untuk meningkatkan mutu pendidikan pada sekolah ini dengan mengembangkan sarana dan prasarana yang berkonsep sehat dan asri. 3) Revitalisasi Kawasan Lingkungan Pendidikan SMPN 03 Batu, Jawa Timur ini menerapkan konsep desain arsitektur berwawasan lingkungan untuk pembelajaran kepada para siswa dan masyarakat sekitar tentang pentingnya menjaga lingkungan, juga dalam wujud pengurangan global warming.

\section{SARAN}

Revitalisasi kawasan lingkungan pendidikan SMPN 03 Batu, Jawa Timur merupakan suatu konsep yang dipengaruhi banyak aspek seperti arsitektur, landscape, struktur, pemanfaatan ruang luar, dan eksterior desainnya. Diharapkan dengan adanya pengembangan sarana prasarana yang berwawasan lingkungan ini warga sekolah dapat tetap menjaga kelestarian lingkungan sekolah. Pelaksanaan setelah perencanaan ini perlu pendampingan secara berkala dalam pembangunannya yaitu : tahap awal untuk dilakukan pemagaran dan pembaharuan pagar, tahap kedua yaitu perluasan area parkir, tahap ketiga yaitu pembaharuan atau renovasi gedung sekolah, dan tahap akhir yaitu penghijauan kembali, area terbuka hijau atau taman. Pada tahap akhir tersebut ditujukan pada akhir perencanaan agar warga sekolah dalam pelaksanaan nantinya dapat berpatisipasi dalam pengembangan, perawatan dan pelestariannya.

\section{DAFTAR RUJUKAN}

Darmawan, B. (2014). Manajemen Sarana dan Prasarana Dalam Meningkatkan Kualitas Pendidikan. Jurnal Pelopor Pendidikan, 6(2), 93-102. Retrieved from http://www.stkippgrismp.ac.id/jurnal-pelopor-pendidikan-4/

Ervianto, W. I., Soemardi, B. W., Abduh, M., \& Surjamanto. (2012). Kajian Reuse Material Bangunan Dalam Konsep Sustainable Construction di Indonesia. Jurnal TEKNIK SIPIL, 12(1), 18-27. 
Simbolon, H., \& Nasution, I. N. (2017). Desain Rumah Tinggal Yang Ramah Lingkungan Untuk Iklim Tropis. Educational Building, 3(1). Https://Doi.Org/10.24114/Eb.V3i1.7443

Sinta, I. M. (2019). Manajemen Sarana Dan Prasarana. Jurnal Isema: Islamic Educational Management, 4(1), 77-92. Https://Doi.Org/10.15575/Isema.V4i1.5645

Sugiyarto, B. (2017). Kajian Jaringan Drainase Kampus UNNES Menuju Sistem Drainase Berwawasan Lingkungan. Jurnal Teknik Sipil Dan Perencanaan, 19(2), 136-142. https://doi.org/10.15294/jtsp.v19i2.11281 